\title{
Outcome and safety of tailored surgical treatments of nonmalignant esophagotracheobronchial fistula: report of fourteen patients
}

This article was published in the following Dove Press journal:

Therapeutics and Clinical Risk Management

\author{
Feng Guo \\ Zhiyong Zhang \\ Yushang Cui \\ Li Li \\ Xiaohui Xu \\ Shanqing Li
}

Department of Thoracic Surgery, Peking Union Medical College Hospital, Peking Union Medical College, Chinese Academy of

Medical Science, Beijing, China
Correspondence: Shanqing $\mathrm{Li}$ Department of Thoracic Surgery, Peking Union Medical College Hospital, Peking Union Medical College, Chinese Academy of Medical Science, No I ShuaiFuYuan Street, Dong Cheng District, Beijing I00730, China

Tel +86 I069152630

Email lishanqing1610@163.com
Introduction: Acquired benign esophageal tracheobronchial fistulae are clinically rare. In this paper, we summarize our experiences in surgical treatment of 14 consecutive patients with acquired benign esophageal tracheobronchial fistula.

Methods: This series included patients who underwent surgery between January 2002 and June 2015 at our institution. We retrieved and analyzed data on demographics, operative characteristics, and surgical outcome of the patients.

Results: Bronchofiberscopy revealed the membranous trachea openings of fistulae and gastroendoscopy further showed lesions in the anterolateral wall of the esophagus. Thoracotomy, division of the fistulous tract, and closure of the esophagus and trachea and other procedures were performed. All operations were uneventful, and there was no perioperative and postoperative complication or death. Symptoms disappeared after surgery in patients. The median length of hospital stay was 53 (range 31-270) days. The patients were followed up for a median of 33.5 (range 15-168) months. No recurrence was reported.

Conclusion: Our results suggest that acquired benign esophageal tracheobronchial fistulae have a broad spectrum of anatomic pathologies and exhibit markedly varied clinical manifestations, and a surgical approach tailored to the condition of individual patients is recommended.

Keywords: esophageal tracheobronchial fistula, surgery, safety

\section{Introduction}

Esophageal tracheobronchial fistula ${ }^{1}$ is an uncommon clinical entity and occurs as a complication of inflammatory disorders, foreign body ingestion, congenital anomalies, or invasion of the trachea or bronchi by malignant esophageal cancer. The majority of benign esophageal tracheobronchial fistulae in adults are acquired, which typically have a protracted course. Acquired benign esophageal tracheobronchial fistulae represent a broad spectrum of anatomic pathologies and exhibit markedly varied clinical manifestations, posing a diagnostic challenge that may lead to delayed or wrong diagnosis.

Acquired benign esophageal tracheobronchial fistulae are clinically rare. Though several clinical series have been reported, ${ }^{2-6}$ the number of patients is small and cases have been accumulated over one or two decades; hence, these cases have varied clinical profiles and have received diverse surgical treatments. Furthermore, although open surgical repair is the traditional treatment of choice, therapeutic guidelines on optimal timing and type of repair for acquired benign esophageal tracheobronchial fistulae are lacking, and multiple surgical options are available, which are based on the location of a fistula, size of the defect, and the extent of organ involvement. ${ }^{1,3,7-11}$ 
In this paper, we summarize our experiences in the surgical treatment of 14 consecutive patients with acquired benign esophageal tracheobronchial fistula and further review some of the reported clinical series of acquired benign esophageal tracheobronchial fistula.

\section{Patients and methods}

\section{Patients}

We analyzed the clinical and surgical data of 14 consecutive patients with a nonmalignant esophageal tracheobronchial fistula who underwent surgery between January 2002 and June 2015 at the Department of Thoracic Surgery, Peking Union Medical Hospital (Beijing, China). The diagnostic investigation included initial chest radiography, barium esophagography, and chest computed tomography (CT) scan for all patients. A water-soluble, radiopaque diagnostic medium (60\% meglumine diatrizoate) was used. After oral ingestion of the medium, the patient was asked to lie in the supine position. The presence of esophageal tracheobronchial fistula was established by demonstrating flow of the radiopaque medium into the respiratory tract. Fiberoptic bronchoscopy and gastroendoscopy were carried out to define the exact site and length of fistulae.

The study was approved by the Ethical Committee at Peking Union Medical Hospital, and patient consent was not required by the committee because of the retrospective nature of the study. Use of patient images was permitted with the written informed consent of the patient, and all patient data were anonymized in the study.

\section{Surgery}

All patients underwent fasting. Duodenal feeding tube or deep vein catheter was placed. Calorie intake requirement was calculated by body weight, and parenteral nutrition was provided for 2 weeks to 1 month. Patients were indicated for thoracotomy 1) if they had chronic cough on ingestion of food or water intake, accompanied with sputum production, and fever; 2) if they had a clear diagnosis and the opening of the fistula was located by gastroendoscopy, bronchofiberscopy, and fistulography, and malignant tumor was excluded by chest CT scan; 3) if they failed conservative therapy including longterm parenteral nutrition, repeated attempts of esophageal stent placement, and endoscopic blockade; and 4) if their infection was controlled and nutritional status was improved, with no other comorbid diseases preventing them from thoracotomy. All patients underwent routine preoperative examinations and for patients with fever and lung infections, sputum culture and antibiotic sensitivity test were carried out and specific antibiotics were given intravenously. Patients underwent surgery once body weight and biochemical parameters became stabilized.

Either left or right thoracotomy was performed. For esophagotracheal fistula, division of the fistulous tract and closure of the esophagus and trachea was carried out, and for bronchoesophageal fistula, division of the fistulous tract and closure of the esophagus and bronchus was done. For thoracogastric airway fistula, division of the fistulous tract and closure of the thoracic stomach and bronchus was undertaken. For fistula between the diverticulum of the esophagus and the bronchus, lower lobectomy and esophagectomy was performed with infra-aortic arch anastomosis of the esophagus with the stomach, or lower lobectomy was carried out with division of the fistulous tract and closure of the diverticulum of the esophagus. Intraoperative images showing division of the fistulous tract and closure of the trachea and esophagus are shown in Figure 1.

\section{Results}

\section{Patient demographic and baseline characteristics}

As shown in Table 1, 14 patients were included in this analysis, with 8 males and 6 females. Their median age was 48.5 (range $32-72$ ) years. Fourteen $(14 / 14,100 \%)$ patients
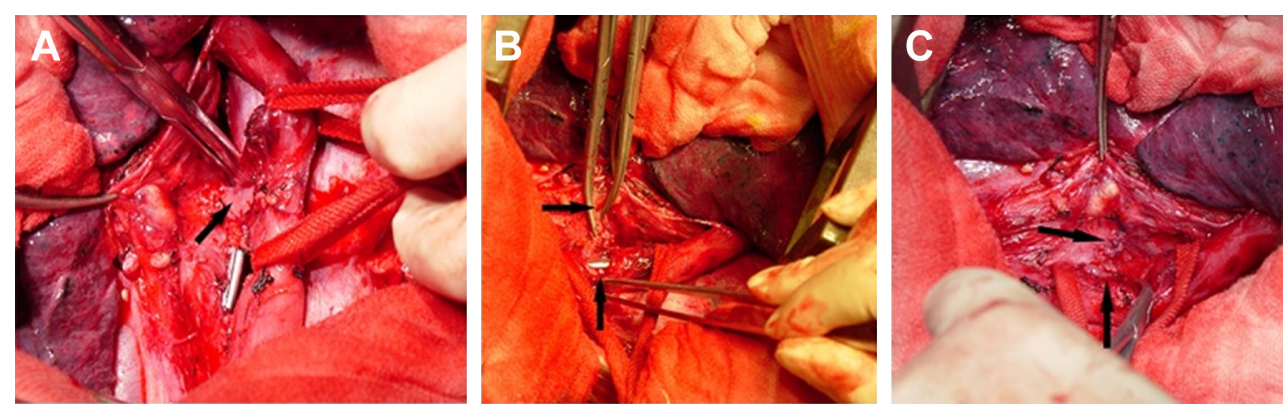

Figure I A 5 I-year-old female with esophagotracheal fistula for 7 months underwent division of the fistulous tract and closure of the trachea and esophagus.

Notes: (A) The tissue flap (arrow) is toward the trachea and before repair the entire opening of the fistula is opened toward the esophagus (tissue on the side of the trachea is scant). (B) The opening (between the vascular clamps) of the fistula is occluded with the tissue flap. Because the tissue flap is pulled toward the trachea, the gastric tube in the esophagus is seen. (C) The opening of the fistula after occlusion with the tissue flap. 
Table I Demographic and baseline information of patients $(\mathrm{N}=14)$

\begin{tabular}{|c|c|c|c|c|c|c|}
\hline No & Gender & $\begin{array}{l}\text { Age } \\
\text { (years) }\end{array}$ & Diagnosis & $\begin{array}{l}\text { Disease } \\
\text { course } \\
\text { (months) }\end{array}$ & $\begin{array}{l}\text { Surgical } \\
\text { approach }\end{array}$ & Type of surgery \\
\hline I & Female & 72 & Esophagotracheal fistula & 3 & Right & $\begin{array}{l}\text { Division of the fistulous tract and closure of the } \\
\text { trachea and esophagus }\end{array}$ \\
\hline 2 & Male & 32 & $\begin{array}{l}\text { Fistula between the diverticulum of the } \\
\text { esophagus and left bronchus }\end{array}$ & 9 & Left & $\begin{array}{l}\text { Left lower lobectomy and lower esophagectomy, and } \\
\text { infra-aortic arch anastomosis of the esophagus with } \\
\text { the stomach }\end{array}$ \\
\hline 3 & Male & 61 & $\begin{array}{l}\text { Fistula between the esophagus and the } \\
\text { left main stem bronchus }\end{array}$ & 1 & Left & $\begin{array}{l}\text { Division of the fistulous tract and closure of the } \\
\text { esophagus and left main stem bronchus }\end{array}$ \\
\hline 4 & Male & 40 & Esophagotracheal fistula & 6 & Right & $\begin{array}{l}\text { Division of the fistulous tract and closure of the } \\
\text { trachea and esophagus }\end{array}$ \\
\hline 5 & Female & 58 & Esophagotracheal fistula & 7 & Right & $\begin{array}{l}\text { Division of the fistulous tract and closure of the } \\
\text { trachea and esophagus }\end{array}$ \\
\hline 6 & Male & 47 & $\begin{array}{l}\text { Fistula between the thoracic stomach and } \\
\text { the left main stem bronchus postsurgery } \\
\text { for esophageal cancer }\end{array}$ & 3 & Right & $\begin{array}{l}\text { Division of the fistulous tract and closure of the } \\
\text { thoracic stomach and the left main stem bronchus }\end{array}$ \\
\hline 7 & Male & 56 & $\begin{array}{l}\text { Fistula between the thoracic stomach and } \\
\text { the right main stem bronchus postsurgery } \\
\text { for esophageal cancer with left thoracic } \\
\text { incision and left cervical incision }\end{array}$ & 2 & Right & $\begin{array}{l}\text { Division of the fistulous tract and closure of the } \\
\text { thoracic stomach and the right main stem bronchus }\end{array}$ \\
\hline 8 & Female & 45 & Esophagotracheal fistula & 3 & Right & $\begin{array}{l}\text { Division of the fistulous tract and closure of the } \\
\text { trachea and esophagus }\end{array}$ \\
\hline 9 & Male & 43 & Esophagotracheal fistula & 4 & Right & $\begin{array}{l}\text { Division of the fistulous tract and closure of the } \\
\text { trachea and esophagus }\end{array}$ \\
\hline 10 & Female & 51 & $\begin{array}{l}\text { Esophagotracheal fistula postoperative } \\
\text { right lower lobectomy }\end{array}$ & 24 & Right & $\begin{array}{l}\text { Division of the fistulous tract and closure of the } \\
\text { bronchus and esophagus }\end{array}$ \\
\hline II & Female & 44 & Esophagotracheal fistula & 15 & Right & $\begin{array}{l}\text { Division of the fistulous tract and closure of the } \\
\text { trachea and esophagus }\end{array}$ \\
\hline 12 & Female & 48 & $\begin{array}{l}\text { Fistula between the diverticulum of the } \\
\text { esophagus and the bronchus }\end{array}$ & 30 & Left & $\begin{array}{l}\text { Left lower lobectomy and division of the fistulous } \\
\text { tract and closure of the diverticulum of the esophagus }\end{array}$ \\
\hline 13 & Male & 49 & Esophagotracheal fistula & 550 & Right & $\begin{array}{l}\text { Division of the fistulous tract and closure of the } \\
\text { trachea and esophagus }\end{array}$ \\
\hline 14 & Male & 59 & $\begin{array}{l}\text { Fistula between the esophagus and the } \\
\text { mid segment of the right bronchus }\end{array}$ & 600 & Right & $\begin{array}{l}\text { Right lower lobectomy and division of the fistulous } \\
\text { tract and closure of the diverticulum of the esophagus }\end{array}$ \\
\hline
\end{tabular}

had chronic productive cough, which was worse upon ingestion, and recurrent episodes of fever. The possible causes of esophagotracheal fistula are listed in Table 1. One patient had previously received right lower lobectomy due to a benign tumor and two patients had undergone surgery for esophageal cancer, with supra-aortic anastomosis in one case and anastomosis in the neck between the left thoracic incision and neck incision in the other. Eight patients had esophageal tracheobronchial fistula for a duration of over 6 months, and they were converted to surgery because they had failed long-term gastroenteral nutritional support or repeated attempts of esophageal stent placement.

Bronchofiberscopy and chest CT scan revealed the membranous trachea openings of fistulae, which varied 2-8 $\mathrm{mm}$ in size (Figure 2A and B). Gastroendoscopy further showed lesions in the anterolateral wall of the esophagus, which were 20-28 cm from the incisor (Figure 2C). The fistula opening was clearly visible in 7 cases, diverticulosis was observed in 4 cases, and small fistula opening was seen in the base of the diverticula in 3 cases, varying $3-10 \mathrm{~mm}$ in size, with occasional air bubbles. Endoscopic biopsy revealed the presence of chronic inflammation, but no tumor or infection was seen. Chest CT scan excluded that esophageal tracheobronchial fistula was caused by esophageal or bronchial tumors.

\section{Surgical characteristics and outcomes}

Left thoracotomy was performed in 3 patients and right thoracotomy in $11(78.6 \%, 11 / 14)$ patients. Division of the fistulous tract and closure of the esophagus and trachea was carried out in 8 patients with esophagotracheal fistula. Furthermore, division of the fistulous tract and closure of the esophagus and bronchus was done in 1 patient with bronchoesophageal fistula. In addition, division of the fistulous tract and closure of the thoracic stomach and bronchus was 

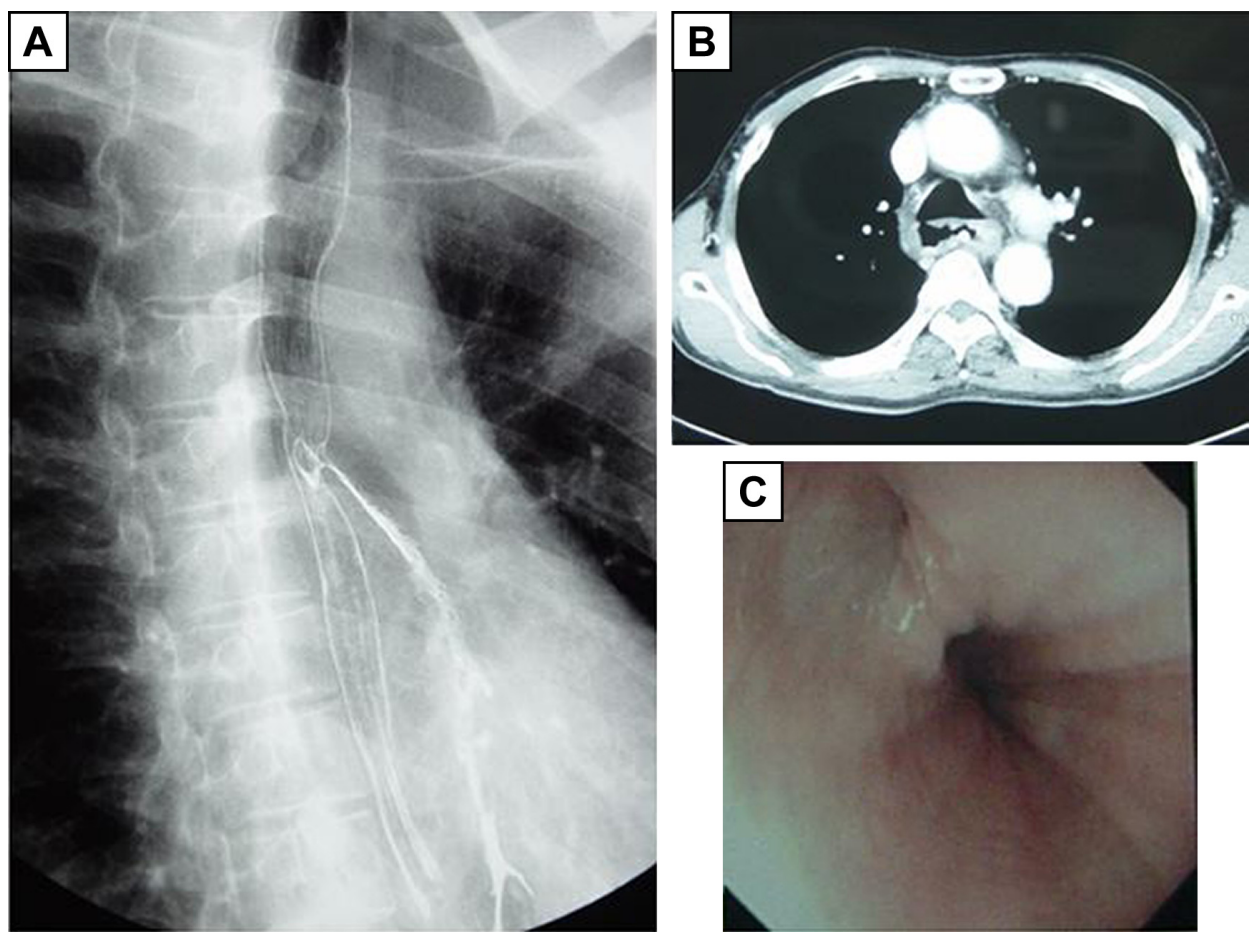

Figure 2 Preoperative diagnostic investigation.

Notes: (A) Esophagography demonstrates the outflow of radiopaque diagnostic medium from the esophagus into the trachea in a $5 \mathrm{I}$-year-old female with esophagotracheal fistula. (B) CT scan shows the opening of the esophagotracheal fistula. (C) Gastroendoscopy reveals the opening of the fistula in the esophagus in the same patient. Abbreviation: CT, computed tomography.

undertaken in 2 patients with thoracogastric airway fistula. For fistula between the diverticulum of the esophagus and the bronchus, lower lobectomy and esophagectomy were performed in 1 patient with infra-aortic arch anastomosis of the esophagus with the stomach (Sweet procedure) and lower lobectomy was carried out in 1 patient with division of the fistulous tract and closure of the diverticulum of the esophagus. The location of the esophagotracheal fistula was determined during the operation (Figure 3). Histologic study

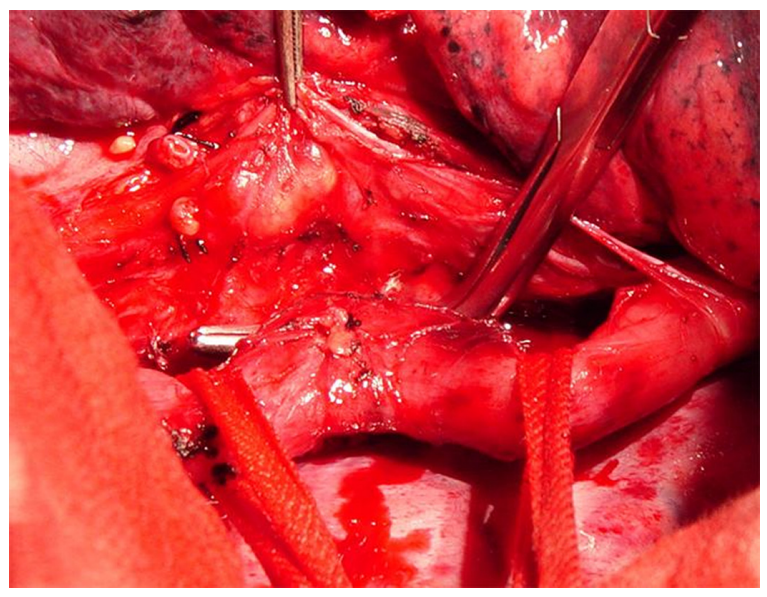

Figure 3 The location of the esophagotracheal fistula is determined during the operation. of the excised specimens revealed no tumor, tuberculosis, or mycological infections.

All operations were uneventful and there was no perioperative complication or death. Symptoms disappeared after surgery in patients and oral intake was resumed 7-10 days postoperatively. The median length of hospital stay was 53 (range 31-270) days.

The patients were followed up for a median duration of 33.5 (range 15-168) months. No recurrence was reported. Fiberoptic bronchoscopy and gastroendoscopy showed no tracheal stenosis or esophageal stenosis, with no need for stenting or dilatation therapy.

\section{Discussion}

We report the surgical outcome of 14 patients with esophageal tracheobronchial fistula. The patients were managed by a diverse array of surgical approaches including division of the fistulous tract and closure of the trachea and esophagus, a left lower lobectomy and lower esophagectomy, and infra-aortic arch anastomosis of the esophagus with the stomach (Sweet procedure). These surgeries were tailored to the particular condition of each patient. Compared with other reported series, ${ }^{3,5,6,11,12}$ no perioperative complications or death occurred and all patients underwent an uneventful recovery and were discharged 5-8 days postoperatively. 
Esophageal tracheobronchial fistula can occur anywhere from the subglottic trachea to the left main stem bronchus. Variable causes contribute to the development of esophageal tracheobronchial fistula. Regardless of the cause of esophageal tracheobronchial fistula, right thoracotomy is undertaken for division of the fistulous tract and closure of the trachea and esophagus. Only when esophagectomy is contemplated in cases with unilateral lesioned lung, different approaches may be undertaken. In this series, we chose right thoracotomy and avoided left thoracotomy for patients with esophagotracheal fistula and thoracogastric airway fistula as these fistulae are mostly located in the upper and mid mediastinum and the presence of the left thoracic aortic arch makes surgical exposure in left thoracotomy difficult. Right thoracotomy, on the other hand, can expose the full length of the thoracic esophagus, which facilitates surgical maneuvering. In cases where left thoracotomy has been undertaken, right thoracotomy may be adopted in reoperation in order to avoid chest adhesions. In cases of bronchial thoracogastric airway fistula and recurrent lung infections, lobectomy may be undertaken and laterality of thoracotomy can be determined ipsilateral to the lung lesion. ${ }^{11}$

Acquired benign esophageal tracheobronchial fistula can be caused by overinflation of a cuffed tracheostomy tube, trauma or iatrogenic injuries, ${ }^{13}$ esophageal stents, ${ }^{14}$ involvement of the esophagus and trachea by adjacent diseased or lesioned organs, ${ }^{8}$ or invasion of the trachea or bronchi by malignant esophageal cancer. For those fistulae due to invasion of the trachea or bronchi by malignant esophageal cancer, the chance for surgical management is rather dim. Lei et al have recently attempted surgical treatment of esophageal tracheobronchial fistula formed due to invasion of the trachea or bronchi by malignant esophageal cancer. ${ }^{15}$ In two of our patients, a fistula was formed between the bronchus and the thoracic stomach as a result of local inflammation, poor drainage, and subsequent infection in the thoracic stomach. The two cases were treated by division of the fistulous tract and closure of the thoracic stomach and left or right main stem

Table 2 Surgical treatments and outcomes of patients with acquired benign esophagorespiratory fistulae in the literature

\begin{tabular}{|c|c|c|c|}
\hline Reference & $\begin{array}{l}\text { Sample } \\
\text { size }\end{array}$ & Intervention & Outcomes \\
\hline $\begin{array}{l}\text { Deshpande } \\
\text { et } \mathrm{al}^{4}\end{array}$ & 12 & $\begin{array}{l}\text { Primary closure of the esophageal defect and reinforcement with pleural or intercostal muscle } \\
\text { flap or a subtotal esophagectomy; primary closure of the respiratory end of the fistula or } \\
\text { neo-membranous airway formation }(n=8)\end{array}$ & Not reported \\
\hline Shen et al' & 35 & $\begin{array}{l}\text { Staged repair }(n=6) \text {, division and primary repair }(n=18) \text {, esophageal resection with } \\
\text { reconstruction }(n=4) \text {, esophageal diversion }(n=6) \text {, suture closure of the esophageal or tracheal } \\
\text { defect only }(n=4) \text {, segmental tracheal or bronchial resection }(n=3)\end{array}$ & $\begin{array}{l}\text { Operative mortality } \\
(n=2) \text {, complications } \\
(n=19) \text {, recurrence }(n=3)\end{array}$ \\
\hline $\begin{array}{l}\text { Muniappan } \\
\text { et al }\end{array}$ & 36 & $\begin{array}{l}\text { Closure of the tracheal defect with resection and reconstruction }(n=I 7) \text {, laryngotracheal } \\
\text { resection }(n=5) \text {, membranous tracheal repair }(n=17) \text {, or repair over a tracheal T tube }(n=2) \text { and } \\
\text { esophageal repair with 2-layer closure }(n=3 I) \text {, I-layer closure }(n=6) \text {, esophagostomy }(n=I) \text {, end- } \\
\text { to-end esophageal anastomosis }(n=I) \text {, or full-thickness skin graft reconstruction }(n=I)\end{array}$ & $\begin{array}{l}\text { Postoperative death } \\
(n=1) \text {, recurrence }(n=4)\end{array}$ \\
\hline $\begin{array}{l}\text { Reed and } \\
\text { Mathisen' }\end{array}$ & 38 & $\begin{array}{l}\text { Simple division and closure of the fistula }(n=9) \text {, tracheal resection and reconstruction }(n=29) \text {, } \\
\text { closure of the esophageal defect in } 2 \text { layers and a viable strap muscle interposed between the } \\
2 \text { suture lines }\end{array}$ & $\begin{array}{l}\text { Death }(n=4) \text {, recurrence } \\
(n=3) \text {, delayed tracheal } \\
\text { stenosis }(n=1)\end{array}$ \\
\hline $\begin{array}{l}\text { Hilgenberg } \\
\text { and Grillo }\end{array}$ & 20 & $\begin{array}{l}\text { Direct closure of the esophageal defect }(n=16) \text {, end-to-end reconstruction of the } \\
\text { esophagus }(n=4)\end{array}$ & $\begin{array}{l}\text { Death }(n=2) \text {, recurrence } \\
(n=1)\end{array}$ \\
\hline 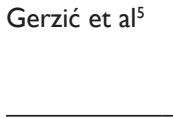 & 16 & $\begin{array}{l}\text { Diverticulectomy, division of the fistula, and suture of both esophageal and respiratory defects } \\
(n=12) \text {; temporary gastrostomy }(n=4)\end{array}$ & $\begin{array}{l}\text { Operative mortality } \\
(\mathrm{n}=\mathrm{I}) \text {, death }(\mathrm{n}=2 \text {, } \\
\text { temporary gastrostomy })\end{array}$ \\
\hline $\begin{array}{l}\text { Cherveniakov } \\
\text { et } \mathrm{al}^{3}\end{array}$ & 35 & $\begin{array}{l}\text { Simple excision of the fistula, longitudinal suture of the trachea and horizontal suture of the } \\
\text { esophagus }(n=9) \text {; circular resection with reconstruction of the trachea and plastic suture } \\
\text { of the esophagus ( } n=6) \text {; esophagectomy with ensuing colon substitution }(n=4) \text {; use of left } \\
\text { sternocleidomastoid flap }(n=12) \text {; palliative therapy }(n=4)\end{array}$ & $\begin{array}{l}\text { Postoperative death } \\
(n=2) \text {, recurrence }(n=4)\end{array}$ \\
\hline Baisi et $\mathrm{al}^{2}$ & 31 & $\begin{array}{l}\text { Dissection of the fistula and closure of the tracheal and esophageal defect }(n=26) \text {, } \\
\text { esophagogastroplasty plus closure of the tracheal defect and omental interposition }(n=2) \text {, } \\
\text { tracheal resection and reconstruction of the sternocleidomastoid muscle interposition }(n=I) \text {, } \\
\text { nonsurgical treatment }(n=2)\end{array}$ & $\begin{array}{l}\text { Postoperative } \\
\text { death }(n=1) \text {, treatment } \\
\text { failure }(n=2)\end{array}$ \\
\hline This study & 14 & $\begin{array}{l}\text { Division of the fistulous tract and closure of the esophagus and trachea }(n=7) \text { or bronchus } \\
(n=2) \text {; division of the fistulous tract and closure of the thoracic stomach and main stem } \\
\text { bronchus }(n=2) \text {; lower lobectomy and division of the fistulous tract and closure of the } \\
\text { diverticulum of the esophagus ( } n=2) \text {; left lower lobectomy and lower esophagectomy, and } \\
\text { infra-aortic arch anastomosis of the esophagus with the stomach }(n=1)\end{array}$ & $\begin{array}{l}\text { No mortality, no } \\
\text { complications, and no } \\
\text { recurrence }\end{array}$ \\
\hline
\end{tabular}


bronchus, with uneventful recovery. We further reviewed some of the reported series of acquired benign esophageal tracheobronchial fistula (Table 2). Spalding et $\mathrm{al}^{16}$ reported a series of 7 patients with acquired nonmalignant bronchoesophageal fistulas. Five patients were treated by a right-sided thoracotomy with division of the fistulous tract and closure of the bronchus and esophagus, and 1 patient required esophageal resection and subsequent reconstruction for permanent fistula closure. Shen et $\mathrm{al}^{11}$ reported a series of 35 patients over a 30 -year period and found single-stage primary repair of both airway and esophageal defects with tissue flap interposition can safely be performed successfully in the majority of patients with acquired nonmalignant bronchoesophageal fistulas. Mangi et al ${ }^{17}$ reported a series of 13 patients with acquired benign bronchoesophageal fistulae who were treated by primary closure of the bronchus and esophagus and interposition of vascularized tissue. There was 1 perioperative failure, but no long-term recurrences after successful surgical closure. Compared to the reported series, we had a $100 \%$ success rate with no one dying during or after surgery. Major contributors, in our opinion, to a successful outcome include a well-established protocol for managing esophageal tracheobronchial fistulae, precise preoperative evaluation, and thorough preoperative preparation. Our tailored approach in deciding to proceed with simple esophageal tracheobronchial fistula repair or lobectomy, or even esophagectomy, also contributes to a satisfactory outcome. Our surgeons are also dexterous in surgical maneuvering, thus avoiding injury to adjacent critical organs and accurately locating the fistula opening, with maximal retention of tissue flaps for repair. In this paper, we only compared patients who were surgically managed by thoracotomy. It is worthy of note that esophageal tracheobronchial fistula is also managed conservatively ${ }^{18}$ or treated endoscopically ${ }^{19}$ with varied results. Ahn et al used endoscopic closure as the primary treatment for 7 patients with benign bronchoesophageal fistula. ${ }^{19}$ All 7 patients failed the first attempt and half (2/4) failed the second attempt, and all these patients were converted to open surgery. Prolonged inflammation around the fistula causes local congestion and swelling, hyperplasia of fibrous tissues, and formation of hard scar. These peri-fistular changes render the surgical procedure more challenging, resulting in failed cases. Eight patients in this series had esophageal tracheobronchial fistula for a duration of over 6 months, and they were converted to surgery because they had failed long-term gastroenteral nutritional support or repeated attempts of esophageal stent placement. It was also reported ${ }^{20}$ that fistula repair under a thoracoscope might be an optimal minimally invasive approach for the treatment of esophageal tracheobronchial fistula. This, however, is limited to a few cases of congenital esophageal tracheobronchial fistula in which adhesion in the mediastinum is not severe. For acquired esophageal tracheobronchial fistula, severe chronic inflammation is present in the mediastinum, leaving no anatomic space, thus rendering thoracoscopic repair difficult to accomplish.

Chronic cough, worsened on ingestion, with recurrent episodes of pulmonary infection and sepsis are characteristic manifestations of esophageal tracheobronchial fistula. Atypical manifestations may cause missed or delayed diagnosis. Barium esophagography in the upright position may miss small fistula openings because of the rapid transit of the water-soluble, radiopaque diagnostic medium; change to the supine position may boost the chance of demonstrating the presence, size, and location of fistula openings. Ancillary examinations such as bronchofiberscopy and gastroendoscopy aid the diagnosis of the disease by directly visualizing the fistula opening and the size of fistulae. Thoracic CT scan also helps rule in or out benign bronchoesophageal fistulae due to malignant causes; in such cases, no surgery is performed.

Esophageal tracheobronchial fistula patients typically have a protracted course with difficult food intake, chronic cough, and recurrent episodes of pulmonary infections. Consequently, a stabilization period has to ensue before proceeding to surgery. Fasting, placement of duodenal feeding tube or deep vein catheter, calorie support, and pulmonary infection control can be employed to stabilize patients. Right thoracotomy is the dominant approach and was done in three-quarters of our patients. Esophagotracheal fistulae and thoracogastric cavity fistulae are mostly located in the upper and mid mediastinum. Left thoracotomy cannot achieve adequate exposure because of the aortic arch. Right thoracotomy exposes the full length of the esophagus, facilitating operative maneuvering. Lobectomy may be performed in thoracogastric cavity fistulae, and thoracotomy ipsilateral to the lungs with infections is done. Stepwise dissection of adherent tissues is performed distal to the fistula opening. In right thoracotomy, the azygos vein is typically dissected, transected, and ligated and the esophagus is dissected in both directions. It is most difficult to dissociate adherent tissues around the esophageal tracheobronchial fistula openings; the esophagus around the fistula opening should not be dissociated from the trachea or bronchus. Tissues around the fistula in the bronchus should be preserved maximally as they can be used as tissue flaps. Tissues around the fistula in the esophagus can be dealt with more liberally, and remnant tissues may be used to strengthen the fistula in the bronchus. In this series, tissue flaps were 
used for successful repair of defects. If the fistula opening is large, such as in iatrogenic injuries, muscle flaps or tissue flaps can be used for repair. ${ }^{9,21,22}$

Lobectomy may be performed in thoracogastric cavity fistulae, and thoracotomy ipsilateral to the lungs with infections is done. Preoperative chest CT scan revealed destructed lungs in 3 of our patients; therefore, simple fistula repair cannot be done. Thoracotomy was done ipsilateral to the destructed lung and lobectomy was carried out concurrently. Fistula opening in the esophagus can be repaired layer by layer, and there is no stenosis and esophagectomy and re-anastomosis are not required in most cases. Two patients in our series had fistula between the diverticulum of the esophagus and left main bronchus; in 1 patient, the diverticulum was tractioned to a 4-5 $\mathrm{mm}$ fistula tube and after ligation and excision, the esophageal diverticulum was sutured and repaired layer by layer and esophagectomy was not performed. In the other patient, inflammation was present in the diverticulum and adjacent esophagus, rendering repair difficult. The diverticulum and lower esophagus were excised and infra-aortic arch anastomosis of the esophagus with the stomach was performed.

In conclusion, our results suggest that acquired benign esophageal tracheobronchial fistulae have a broad spectrum of anatomic pathologies and exhibit markedly varied clinical manifestations, and a surgical approach tailored to the condition of individual patients is recommended.

\section{Disclosure}

The authors report no conflicts of interest in this work.

\section{References}

1. Reed MF, Mathisen DJ. Tracheoesophageal fistula. Chest Surg Clin N Am. 2003;13(2):271-289.

2. Baisi A, Bonavina L, Narne S, Peracchia A. Benign tracheoesophageal fistula: results of surgical therapy. Dis Esophagus. 1999;12(3):209-211.

3. Cherveniakov A, Tzekov C, Grigorov GE, Cherveniakov P. Acquired benign esophago-airway fistulas. Eur J Cardiothorac Surg. 1996;10(9): 713-716.

4. Deshpande G, Samarasam I, Banerjee S, Gnanamuthu RB, Chandran S, Mathew G. Benign esophagorespiratory fistula: a case series and a novel technique of definitive management. Dis Esophagus. 2013;26(2): 141-147.
5. Gerzić Z, Rakić S, Randjelović T. Acquired benign esophagorespiratory fistula: report of 16 consecutive cases. Ann Thorac Surg. 1990; 50(5):724-727.

6. Hilgenberg AD, Grillo HC. Acquired nonmalignant tracheoesophageal fistula. J Thorac Cardiovasc Surg. 1983;85(4):492-498.

7. Bardini R, Radicchi V, Parimbelli P, Tosato SM, Narne S. Repair of a recurrent benign tracheoesophageal fistula with a gore-tex membrane. Ann Thorac Surg. 2003;76(1):304-306.

8. Camargo JJ, Machuca TN, Camargo SM, Lobato VF, Medina CR. Surgical treatment of benign tracheo-oesophageal fistulas with tracheal resection and oesophageal primary closure: is the muscle flap really necessary? Eur J Cardiothorac Surg. 2010;37(3):576-580.

9. Chappell VL, Heck HA Jr. Repair of large, iatrogenic, tracheoesophageal fistulae. Ann Thorac Surg. 2007;83(2):705-706.

10. Marzelle J, Dartevelle P, Khalife J, Rojas-Miranda A, Chapelier A, Levasseur P. Surgical management of acquired post-intubation tracheooesophageal fistulas: 27 patients. Eur J Cardiothorac Surg. 1989;3(6): 499-502; discussion 502-503.

11. Shen KR, Allen MS, Cassivi SD, et al. Surgical management of acquired nonmalignant tracheoesophageal and bronchoesophageal fistulae. Ann Thorac Surg. 2010;90(3):914-918; discussion 919.

12. Muniappan A, Wain JC, Wright CD, et al. Surgical treatment of nonmalignant tracheoesophageal fistula: a thirty-five year experience. Ann Thorac Surg. 2013;95(4):1141-1146.

13. Macchiarini P, Verhoye JP, Chapelier A, Fadel E, Dartevelle P. Evaluation and outcome of different surgical techniques for postintubation tracheoesophageal fistulas. J Thorac Cardiovasc Surg. 2000;119(2): 268-276.

14. Han Y, Liu K, Li X, et al. Repair of massive stent-induced tracheoesophageal fistula. J Thorac Cardiovasc Surg. 2009;137(4):813-817.

15. Lei J, Zhang N, Luo Q, Gao K, Yang E, Wang X. Surgical Treatment of Esophagobronchial Fistula Induced by Esophageal Carcinoma. Chinese J Clin Thorac Cardiovasc Surg. 2012;19(1):36-38.

16. Spalding AR, Burney DP, Richie RE. Acquired benign bronchoesophageal fistulas in the adult. Ann Thorac Surg. 1979;28(4):378-383.

17. Mangi AA, Gaissert HA, Wright CD, et al. Benign broncho-esophageal fistula in the adult. Ann Thorac Surg. 2002;73(3):911-915.

18. Zhou N, Chen WX, Li YM, Xiang Z, Gao P, Fang Y. Successful tubes treatment of esophageal fistula. J Zhejiang Univ Sci B. 2007;8(10): 709-714.

19. Ahn JY, Jung HY, Choi JY, et al. Benign bronchoesophageal fistula in adults: endoscopic closure as primary treatment. Gut Liver. 2010;4(4): 508-513.

20. Ginesu GC, Feo CF, Cossu ML, et al. Thoracoscopic treatment of a broncho-esophageal fistula: a case report. Int J Surg Case Rep. 2016; 28:74-77.

21. Golash V. Single-stage repair of a large acquired tracheoesophageal fistula with interposition of 2 muscle pedicle flaps and laparoscopic gastrojejunostomy. J Thorac Cardiovasc Surg. 2006;131(6):1413-1414.

22. Talbot ML, Hugh TB, Spratt P. Gastric antral patch oesophagoplasty for iatrogenic tracheo-oesophageal fistula. ANZ J Surg. 2007;77(4): 295-297.
Therapeutics and Clinical Risk Management

\section{Publish your work in this journal}

Therapeutics and Clinical Risk Management is an international, peerreviewed journal of clinical therapeutics and risk management, focusing on concise rapid reporting of clinical studies in all therapeutic areas, outcomes, safety, and programs for the effective, safe, and sustained use of medicines. This journal is indexed on PubMed Central, CAS,

\section{Dovepress}

EMBase, Scopus and the Elsevier Bibliographic databases. The manuscript management system is completely online and includes a very quick and fair peer-review system, which is all easy to use. Visit http://www.dovepress.com/testimonials.php to read real quotes from published authors. 